\title{
Conscious Expectation and Unconscious Conditioning in Analgesic, Motor, and Hormonal Placebo/Nocebo Responses
}

\author{
Fabrizio Benedetti, ${ }^{1,2}$ Antonella Pollo, ${ }^{1,2}$ Leonardo Lopiano, ${ }^{1}$ Michele Lanotte, ${ }^{4}$ Sergio Vighetti, ${ }^{1}$ and \\ Innocenzo Rainero ${ }^{1,3}$ \\ ${ }^{1}$ Department of Neuroscience, ${ }^{2}$ Clinical and Applied Physiology Program, and ${ }^{3}$ Neurology III-Headache Center, University of Turin Medical School, Turin, \\ Italy 10125, and ${ }^{4}$ Division of Neurosurgery, CTO Medical Center, Turin, Italy 10126
}

\begin{abstract}
The placebo and nocebo effect is believed to be mediated by both cognitive and conditioning mechanisms, although little is known about their role in different circumstances. In this study, we first analyzed the effects of opposing verbal suggestions on experimental ischemic arm pain in healthy volunteers and on motor performance in Parkinsonian patients and found that verbally induced expectations of analgesia/hyperalgesia and motor improvement/worsening antagonized completely the effects of a conditioning procedure. We also measured the effects of opposing verbal suggestions on hormonal secretion and found that verbally induced expectations of increase/ decrease of growth hormone (GH) and cortisol did not have any effect on the secretion of these hormones. However, if a preconditioning was performed with sumatriptan, a 5- $\mathrm{HT}_{1 \mathrm{~B} / 1 \mathrm{D}}$ agonist that stimulates $\mathrm{GH}$ and inhibits cortisol secretion, a significant increase of $\mathrm{GH}$ and decrease of cortisol plasma concentrations were found after placebo administration, although opposite verbal suggestions were given. These findings indicate that verbally induced expectations have no effect on hormonal secretion, whereas they affect pain and motor performance. This suggests that placebo responses are mediated by conditioning when unconscious physiological functions such as hormonal secretion are involved, whereas they are mediated by expectation when conscious physiological processes such as pain and motor performance come into play, even though a conditioning procedure is performed.
\end{abstract}

Key words: expectation; conditioning; placebo; pain; Parkinson's disease; hormones

\section{Introduction}

The placebo effect is a widespread phenomenon in medicine and biology, although its underlying psychological and neurobiological mechanisms are still poorly understood. Placebo analgesia has been shown to be one of the most successful models in the study of the placebo effect, from both the neuropharmacological (Levine et al., 1978; Grevert et al., 1983; Levine and Gordon, 1984; Benedetti, 1996; Amanzio and Benedetti, 1999; Benedetti et al., 1999b) and neuroanatomical viewpoints (Petrovic et al., 2002). In addition, the study of the placebo effect in Parkinson's disease (de la Fuente-Fernandez et al., 2001, Pollo et al., 2002) and depression (Leuchter et al., 2002; Mayberg et al., 2002) has shown that placebos can be investigated from a neurobiological perspective not only in the field of pain.

The mechanisms leading to the release of endogenous opioids in placebo analgesia (Amanzio and Benedetti, 1999; Benedetti et al., 1999b) and of endogenous dopamine in the placebo response of Parkinsonian patients (de la Fuente-Fernandez et al., 2001) are believed to involve both conditioning and cognitive factors (Price and Fields, 1997; Price, 2002). In fact, if humans or animals are exposed to a biologically active medication, the efficacy of a subsequently administered placebo that physically resembles the initial active drug will be enhanced (Laska and Sunshine, 1973; Ader, 1997; Amanzio and Benedetti, 1999; Benedetti et al., 1999a;

\footnotetext{
Received Dec. 2, 2002; revised Jan. 31, 2003; accepted Feb. 7, 2003.

This work was supported by grants from the Italian Ministerio dell'Istruzione Università e Ricerca and from the Consiglio Nazionale delle Ricerche Project "Neuroscience."

Correspondence should be addressed to Fabrizio Benedetti, Dipartimento di Neuroscienze, Università di Torino Corso Raffaello 30, 10125 Torino, Italy. E-mail: fabrizio.benedetti@unito.it

Copyright $\odot 2003$ Society for Neuroscience $\quad$ 0270-6474/03/234315-09\$15.00/0
}

Siegel, 2002). This observation suggests that classical conditioning of contextual cues associated with drug action can contribute to the placebo response. In other studies, the deceptive administration of a placebo treatment can lead the subjects to believe that the treatment is effective (Kirsch and Weixel, 1988; Kirsch, 1999). In this situation, the expectation of analgesia leads to a significant placebo analgesic effect (Amanzio and Benedetti, 1999; Benedetti et al., 1999b; Price et al., 1999; Pollo et al., 2001).

Surprisingly, a few studies have attempted to assess the differential role of conditioning and expectation in evoking a placebo response, and indeed the findings do not coincide (Voudouris et al., 1985, 1989, 1990; Montgomery and Kirsch, 1997). However, these two mechanisms do not have to be mutually exclusive, because both can play a role in different circumstances (Amanzio and Benedetti, 1999; Price et al., 1999). It is worth noting that the distinction between conditioning and expectation goes beyond the understanding of the placebo effect itself. In fact, alternative models of learning argue that what is learned in Pavlovian conditioning is an expectation of the occurrence or nonoccurrence of an unconditioned stimulus (Reiss, 1980; Rescorla, 1988).

On the basis of these considerations, we investigated the role of expectation and conditioning in different placebo responses. On the one hand we studied pain in healthy volunteers and motor performance in Parkinsonian patients; on the other hand we analyzed two totally unconscious physiological processes, that is, the secretion of growth hormone $(\mathrm{GH})$ and cortisol.

\section{Materials and Methods \\ Pain}

Subjects. A total of 60 healthy volunteers participated in the study after they signed a written informed consent form in which the experimental 
Table 1. Characteristics of the subjects who underwent experimental ischemic arm pain

\begin{tabular}{llll}
\hline Group & Sex (male/female) & Age (years) & Weight $(\mathrm{kg})$ \\
\hline 1 & $7 / 7$ & $45.1 \pm 7.5$ & $58.9 \pm 11.1$ \\
2 & $6 / 6$ & $46.9 \pm 8.8$ & $60.6 \pm 10.5$ \\
3 & $5 / 7$ & $45.8 \pm 9.4$ & $62.5 \pm 9.7$ \\
4 & $5 / 6$ & $44.1 \pm 9.7$ & $59.9 \pm 10.3$ \\
5 & $6 / 5$ & $46.4 \pm 7.5$ & $60.5 \pm 9.8$ \\
\hline
\end{tabular}

procedure and the use of ketorolac were described in detail. Each subject underwent a clinical examination in which blood pressure and electrocardiogram were recorded. Subjects with heart problems were not allowed to participate in the study. Most of the subjects reported a previous experience with analgesics, either opioids or nonopioids, for different types of pathological conditions (e.g., headache or previous surgery). All of the experimental procedures were conducted in conformance with the policies and principles contained in the Declaration of Helsinki. The 60 subjects were subdivided into five groups, whose characteristics are shown in Table 1. It should be noted that the ratio of males to females, age, and weight did not differ among the various groups.

Pain induction. Pain was induced experimentally by means of the tourniquet technique, according to the procedures described by Amanzio and Benedetti (1999). Briefly, the subject reclined on a bed, his or her nondominant forearm was extended vertically, and venous blood was drained by means of an Esmarch bandage. A sphygmomanometer was placed around the upper arm and inflated to a pressure of $300 \mathrm{mmHg}$. The Esmarch bandage was maintained around the forearm, which was lowered on the subject's side. After this, the subject started squeezing a hand spring exerciser 12 times while his or her arm rested on the bed. Each squeeze was timed to last $2 \mathrm{sec}$, followed by a $2 \mathrm{sec}$ rest. The force necessary to bring the handles together was $7.2 \mathrm{~kg}$. This type of ischemic pain increases over time very quickly, and the pain becomes unbearable after 13-14 min (Amanzio and Benedetti, 1999). A timer was started after the last squeeze, and the subject stopped the timer when the pain became unbearable. At this point, the experiment was discontinued, and the time was recorded. Thus, pain tolerance was defined as the time from the last squeeze to unbearable pain.

Experimental design. The experiments were performed according to a randomized double-blind design in which neither the subject nor the experimenter knew what drug was being administered. To do this, either ketorolac or saline solution was given. To avoid a large number of subjects, when the saline injection had to be performed in groups 2, 3, 4 and 5 , two or three subjects per group received ketorolac and were interspersed among those who received the saline injection. Those subjects who received ketorolac in place of saline were not included in the study because they were used only to allow the double-blind design. All of the injections were performed $10 \mathrm{~min}$ before the sphygmomanometer cuff was inflated, and the time interval from cuff inflation to the last squeeze was $1 \mathrm{~min}$. Thus, the time interval from drug administration to last squeeze was the same in all subjects (11 $\mathrm{min}$ ).

The complete experimental procedure is shown in Figure 1 (Pain). Group 1 (natural history; $n=14$ ) was tested with the tourniquet technique for 4 consecutive days without receiving any treatment. Group 2 $(n=12)$ received an injection of saline solution $(\mathrm{NaCl} 0.9 \%)$ on day 2 and was told that it was a powerful painkiller, a verbal suggestion aimed at inducing expectation of analgesia. Group $3(n=12)$ received an injection of saline on day 2 and was told that it was a drug that increased pain (expectation of hyperalgesia). Group $4(n=11)$ was treated with ketorolac tromethamine on days 2 and 3 (conditioning) and received an injection of saline on day 4 , with the verbal suggestion that it was ketorolac (expectation of analgesia). The dose of ketorolac was $0.42 \mathrm{mg} / \mathrm{kg}$ in sterile solution of $\mathrm{NaCl} 0.9 \%$, with an infusion rate of $0.1 \mathrm{ml} / \mathrm{sec}$ and a total infusion time ranging from 70 to $110 \mathrm{sec}$. Group $5(n=11)$ was treated with ketorolac on days 2 and 3 (conditioning) and received an injection of saline on day 4 , with the verbal suggestion that it was a drug that increased pain (expectation of hyperalgesia).

\section{Parkinson's disease}

Subjects. Ten patients participated in the study after written informed consent was obtained. They were diagnosed with idiopathic Parkinson's disease, and clinical evaluation was performed by means of the Unified Parkinson's Disease Rating Scale (Fahn et al., 1987). The five stages of the disease, of which stage 5 is the most severe, were also assessed. Table 2 shows the stage for each patient before and after the surgical implantation of the electrodes, as well as the history of the disease and the time from surgery. Any pharmacological treatment was stopped the day before the experimental procedures and did not have carryover effects lasting $>24 \mathrm{hr}$. The electrodes were implanted bilaterally in the subthalamic nuclei according to the usual neurosurgical procedures (Hutchinson et al., 1998; Limousin et al., 1998; Benazzouz and Hallett, 2000; Lopiano et al., 2001; Rizzone et al., 2001). The stimulation parameters (intensity, frequency, and pulse width) for each patient are shown in Table 2.

Measurement of motor performance. Each patient was tested for the velocity of movement of their right hand according to a double-blind experimental design in which neither the patient nor the experimenter knew whether the stimulator was turned off. The velocity of hand movement was assessed by means of a movement analyzer (EB Neuro, Florence, Italy), which is characterized by a $30 \times 25 \mathrm{~cm}$ rectangular surface on which the patients performed a visual directional-choice task (Zappia et al., 1994). To do this, the right index finger was positioned on a central sensor with a green light. After a random interval of a few seconds, a red light turned on randomly in one of three sensors placed $10 \mathrm{~cm}$ away from the green-light sensor. The patients were instructed to move their hand as quickly as possible to reach the target red-light sensor. The movement time was measured by a computer and expressed as the time between the release of the central green-light sensor and the reaching of the target red-light sensor. The mean velocity of movement was expressed as the ratio between the distance between the sensors and the movement time. In each test, 15 consecutive movement time trials were performed; their average represented the final value for that test. Before testing, each patient was allowed to practice with the apparatus.

Experimental design. To check and set the stimulation parameters for clinical and therapeutic purposes, in all of the patients the stimulator had been turned off many times, from the electrode implantation to our experimental procedure. Figure 1 shows that movement velocity was tested 4 and 2 weeks before the experiment session. Three experimental conditions were analyzed on 3 different days, and their order was changed for each patient. In condition 1 the patients received no treatment; that is, the stimulator was kept on and the patient did not receive any verbal instruction. In condition 2 they were told that the stimulator was going to be turned off, but actually it was kept on. It is important to point out that this procedure represents routine clinical practice, in which the patients are informed that the stimulator will be switched off. This can be considered a nocebo procedure, in which expectation of a worsening of motor performance is induced verbally. In condition 3 they were told that the stimulation intensity was going to be increased to improve motor performance, but actually no change in stimulus intensity was made. This can be considered a placebo procedure, in which expectation of an improvement of motor performance is induced verbally. The measurements of hand movement velocity were performed just before the verbal instructions and after $30 \mathrm{~min}$.

\section{Hormones}

Subjects. A total of 95 healthy volunteers participated in this part of the study. The same inclusion and exclusion criteria described previously for pain were followed. They were subdivided into nine groups, the characteristics of which are shown in Table 3.

Plasma concentration assessment. Plasma concentrations of GH and cortisol were assessed in different situations (see below) according to routine clinical practice and as described previously (Rainero et al., 2001, 2002). Briefly, blood samples were collected at different times (see below) in sterile tubes and immediately centrifuged at $4^{\circ} \mathrm{C}$, and the plasma was stored at $-80^{\circ} \mathrm{C}$ until assayed. Plasma $\mathrm{GH}$ concentrations were measured using a commercially available IRMA kit (HGH-CTK and CORTCTK-125; Sorin, Saluggia, Italy). The sensitivity of the GH assay was 0.15 $\mu \mathrm{g} / \mathrm{l}$, and the intra-assay and inter-assay coefficients of variation were 2.6 


\begin{tabular}{|c|c|c|c|c|c|}
\hline P a i n & Day 1 & Day 2 & Day 3 & Day 4 & Day 5 \\
\hline Group 1 & No treatment & No treatment & No treatment & No treatment & - \\
\hline Group 2 & No treatment & $\begin{array}{c}\text { Suggestion of } \\
\text { analgesia }\end{array}$ & No treatment & - & - \\
\hline Group 3 & No treatment & $\begin{array}{l}\text { Suggestion of } \\
\text { hyperalgesia }\end{array}$ & No treatment & - & - \\
\hline Group 4 & No treatment & Ketorolac & Ketorolac & $\begin{array}{c}\text { Suggestion of } \\
\text { analgesia }\end{array}$ & No treatment \\
\hline Group 5 & No treatment & Ketorolac & Ketorolac & $\begin{array}{l}\text { Suggestion of } \\
\text { hyperalgesia }\end{array}$ & No treatment \\
\hline
\end{tabular}

\section{Parkinson's disease}

\section{4 weeks before experiment}
2 weeks before experiment

\section{Experiment}

\section{No treatment}

Suggestion of movement velocity decrease

Suggestion of

Condition $3 \quad \begin{gathered}n \text { times } \\ \text { Stimulator off }\end{gathered}$ Stimulator off $\quad$ Stimulator off $\begin{gathered}\text { movement velocity } \\ \text { increase }\end{gathered}$

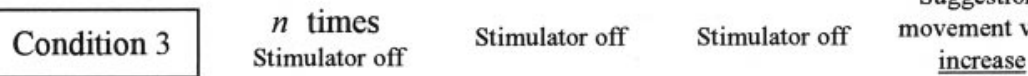

\section{Hormones}

\section{Day 1 Day 2 Day 3}

\begin{tabular}{|c|c|c|c|c|c|c|c|}
\hline Group 1 & $\begin{array}{c}\text { No } \\
\text { treatment }\end{array}$ & $\begin{array}{c}\text { No } \\
\text { treatment }\end{array}$ & $\begin{array}{c}\text { No } \\
\text { treatment }\end{array}$ & & Day 1 & Day 2 & Day 3 \\
\hline Group 2 & $\begin{array}{l}\text { Suggestion } \\
\text { of } \mathrm{GH} \\
\text { increase }\end{array}$ & - & - & Group 6 & $\begin{array}{c}\text { Suggestion of } \\
\text { cortisol } \\
\text { decrease }\end{array}$ & - & - \\
\hline Group 3 & $\begin{array}{l}\text { Suggestion } \\
\text { of GH } \\
\text { decrease }\end{array}$ & - & - & Group 7 & $\begin{array}{l}\text { Suggestion of } \\
\text { cortisol } \\
\text { increase }\end{array}$ & - & - \\
\hline Group 4 & Sumatriptan & Sumatriptan & $\begin{array}{l}\text { Suggestion } \\
\text { of GH } \\
\text { increase }\end{array}$ & Group 8 & Sumatriptan & Sumatriptan & $\begin{array}{l}\text { Suggestion of } \\
\text { cortisol } \\
\text { decrease }\end{array}$ \\
\hline Group 5 & Sumatriptan & Sumatriptan & $\begin{array}{l}\text { Suggestion } \\
\text { of GH } \\
\text { decrease }\end{array}$ & Group 9 & Sumatriptan & Sumatriptan & $\begin{array}{l}\text { Suggestion of } \\
\text { cortisol } \\
\text { increase }\end{array}$ \\
\hline
\end{tabular}

Figure 1. Experimental and control groups for each experimental paradigm (pain, Parkinson's disease, hormone secretion) used in the present study.

and $5.1 \%$. The sensitivity of cortisol was $0.5 \mathrm{ng} / \mathrm{ml}$, and the intra-assay and inter-assay coefficients of variation were 3.8 and $5.7 \%$. All of the samples from each subject were analyzed in the same assay.

Experimental design. The subjects were subdivided into nine groups
(Table 3), and all of the experiments were performed at 9:00 A.M. after an indwelling intravenous catheter had been inserted into a forearm vein to take blood samples. All of the experiments were performed according to a randomized double-blind design in which neither the subject nor the 
Table 2. Characteristics of the patients and stimulation parameters of the subthalamic nuclei for optimal therapeutic effect

\begin{tabular}{|c|c|c|c|c|c|c|c|c|c|c|c|}
\hline \multirow[b]{2}{*}{ Patient } & \multirow[b]{2}{*}{$\begin{array}{l}\text { Age } \\
\text { (years) }\end{array}$} & \multirow[b]{2}{*}{ Sex } & \multirow{2}{*}{$\begin{array}{l}\text { History of } \\
\text { Parkinson's } \\
\text { disease } \\
\text { (years) }\end{array}$} & \multirow{2}{*}{$\begin{array}{l}\text { Time from } \\
\text { surgery } \\
\text { (months) }\end{array}$} & \multirow{2}{*}{$\begin{array}{l}\text { Stage of } \\
\text { disease } \\
\text { before/after } \\
\text { surgery }\end{array}$} & \multicolumn{3}{|c|}{ Left nucleus } & \multicolumn{3}{|c|}{ Right nucleus } \\
\hline & & & & & & $\begin{array}{l}\text { Int } \\
(V)\end{array}$ & $\begin{array}{l}\text { Freq } \\
(\mathrm{Hz})\end{array}$ & $\begin{array}{l}\text { Width } \\
\text { ( } \mu \text { sec) }\end{array}$ & $\begin{array}{l}\text { Int } \\
\text { (V) }\end{array}$ & $\begin{array}{l}\text { Freq } \\
(\mathrm{Hz})\end{array}$ & $\begin{array}{l}\text { Width } \\
\text { ( } \mu \text { sec) }\end{array}$ \\
\hline 1 & 51 & female & 25 & 19 & $4.5 / 3$ & 3.6 & 130 & 60 & 3.6 & 135 & 60 \\
\hline 2 & 69 & male & 15 & 14 & $4 / 2$ & 3.6 & 170 & 90 & 3.6 & 170 & 90 \\
\hline 3 & 57 & female & 13 & 20 & $4 / 2$ & 3.6 & 160 & 60 & 3.6 & 135 & 60 \\
\hline 4 & 70 & female & 19 & 27 & $4 / 2.5$ & 3.3 & 130 & 90 & 3.6 & 135 & 60 \\
\hline 5 & 62 & male & 12 & 7 & $3 / 0.5$ & 3.5 & 135 & 60 & 3.3 & 130 & 60 \\
\hline 6 & 46 & female & 9 & 5 & $2.5 / 2$ & 3.6 & 130 & 90 & 3.6 & 170 & 90 \\
\hline 7 & 61 & male & 12 & 20 & $4 / 0.5$ & 3.5 & 135 & 90 & 3.5 & 130 & 90 \\
\hline 8 & 67 & male & 10 & 18 & $3 / 1.5$ & 3.5 & 160 & 60 & 3.5 & 130 & 90 \\
\hline 9 & 57 & male & 8 & 9 & $4 / 3$ & 3.4 & 135 & 90 & 3.6 & 130 & 90 \\
\hline 10 & 68 & male & 19 & 9 & $4.5 / 2.5$ & 3.6 & 130 & 60 & 3.6 & 130 & 60 \\
\hline
\end{tabular}

Intensity (Int) is expressed in volts (V), frequency (Freq) in Hertz, and pulse width in microseconds ( $\mu$ sec).

Table 3. Characteristics of the subjects who were tested for hormonal responses

\begin{tabular}{llll}
\hline Group & Sex (male/female) & Age (years) & Weight $(\mathrm{kg})$ \\
\hline 1 & $8 / 7$ & $47.4 \pm 10.5$ & $64.7 \pm 12.5$ \\
2 & $5 / 4$ & $49.3 \pm 11.8$ & $65.6 \pm 11.7$ \\
3 & $5 / 6$ & $49.1 \pm 10.4$ & $64.4 \pm 12.6$ \\
4 & $5 / 4$ & $50.1 \pm 9.5$ & $61.6 \pm 12.9$ \\
5 & $5 / 6$ & $48.7 \pm 10.1$ & $65.5 \pm 11.4$ \\
6 & $4 / 5$ & $47.0 \pm 9.2$ & $61.9 \pm 12$ \\
7 & $5 / 5$ & $49.0 \pm 11.2$ & $63.4 \pm 13.1$ \\
8 & $5 / 5$ & $50.8 \pm 10.7$ & $62.9 \pm 12.4$ \\
9 & $5 / 6$ & $48.4 \pm 9.9$ & $63.8 \pm 11.8$ \\
\hline
\end{tabular}

experimenter knew what drug was being administered. To do this, either sumatriptan (see below) or saline solution was given. To avoid using a large number of subjects, when the saline injection had to be performed in groups $2,3,4,5,6,7,8$, and 9 , two or three subjects per group received sumatriptan and were interspersed among those who received the saline injection. Those subjects who received sumatriptan in place of saline were not included in the study because they were used only to allow the double-blind design. No perceptible effect of sumatriptan was reported by these subjects. Figure 1 shows the experimental design (Hormones). Group 1 (natural history; $n=15$ ) received no treatment and was used to check for intra-day and inter-day variations of both plasma GH and plasma cortisol. To do this, a total of seven blood samples were taken every $15 \mathrm{~min}$ for a total time of $90 \mathrm{~min}$. This procedure was repeated for 3 consecutive days. Groups 2, 3, 4, and 5 were tested for GH response. Group $2(n=9)$ received a subcutaneous injection of saline solution $(\mathrm{NaCl} 0.9 \%)$ in the lateral region of the thigh and was told that $\mathrm{GH}$ was going to increase. Blood samples were taken $15 \mathrm{~min}$ before the injection, immediately after the injection ( $0 \mathrm{~min}$ ), and at 15, 30, 45, 60, and $75 \mathrm{~min}$ after the injection. Group $3(n=11)$ underwent the same procedure but was told that GH was going to decrease. Group $4(n=9)$ and group 5 $(n=11)$ were given the same saline injection with the same verbal instructions as groups 2 and 3, respectively, but after a preconditioning with sumatriptan, a highly selective $5-\mathrm{HT}_{1 \mathrm{~B} / 1 \mathrm{D}}$ receptor agonist that stimulates GH secretion and inhibits cortisol secretion (Franceschini et al., 1994; Entwisle et al., 1995; Mota et al., 1995; Valverde et al., 2000; Rainero et al., 2001, 2002). As shown in Figure 1, in the preconditioning procedure, a $6 \mathrm{mg}$ dose of sumatriptan was given subcutaneously in the lateral region of the thigh for 2 consecutive days.

Groups 6, 7, 8, and 9 were tested for cortisol. Figure 1 shows that group $6(n=9)$ was given a subcutaneous injection of saline solution and told that cortisol was going to decrease, whereas group $7(n=10)$ was told that cortisol was going to increase. Group $8(n=10)$ and group $9(n=$ 11) were given the same saline injection and the same verbal instructions as groups 6 and 7 , respectively, but after a preconditioning with sumatriptan. As described above, blood samples were taken $15 \mathrm{~min}$ before the injection, right after the injection ( $0 \mathrm{~min}$ ), and at $15,30,45,60$, and $75 \mathrm{~min}$ after the injection.
Statistical analysis. Statistical analysis was performed by means of oneway ANOVA and ANOVA for repeated measures, followed by the post hoc Newman-Keuls test for multiple comparisons and Dunnett test for comparisons between a control group and different experimental groups. Data are presented as mean $\pm \mathrm{SD}$, and the level of significance is $p<0.05$.

\section{Results \\ Pain}

The natural history of pain tolerance over a $4 \mathrm{~d}$ period is shown in Figure $2 A$. It is possible to see that no differences were found on different days $\left(F_{(3,39)}=1.473 ; p=0.232\right)$. If suggestion of analgesia was given through the administration of a placebo on day 2 (Fig. 2B), a significant increase in pain tolerance occurred $\left(F_{(2,22)}=7.84 ; p<0.03\right)$. Likewise, if suggestion of hyperalgesia was given through a nocebo procedure on day 2 (Fig. $2 C$ ), a significant decrease in pain tolerance was found $\left(F_{(2,22)}=18.12\right.$; $p<0.002$ ). After preconditioning with ketorolac (Fig. $2 D$ ), we found that the placebo effect was larger than the verbal suggestion alone of Figure $2 B\left(F_{(1,21)}=4.38 ; p<0.05\right)$. However, after ketorolac preconditioning, no placebo effect occurred if suggestion of hyperalgesia was given (Fig. 2 E). In addition, pain tolerance on day 4 was significantly lower than the no-treatment on days 1 and $5\left(F_{(2,20)}=5.89 ; p<0.04\right)$. Thus, verbally induced expectation plays a crucial role in each of these experimental conditions, even after the pharmacological preconditioning with ketorolac.

\section{Parkinson's disease}

Figure 3 shows that the subthalamic stimulator of the Parkinsonian patients was turned off several times before the experimental sessions. However, we only have the measurements of hand movement velocity at 4 and 2 weeks before the experimental sessions. It can be seen that every time the stimulator was turned off, the velocity of hand movement slowed down very quickly, and motor performance was poor after $30 \mathrm{~min}$. If a sham turning off of the stimulator was performed (nocebo), a significant decrease of movement velocity occurred (Fig. 3, black circles) $\left(F_{(1,9)}=5.24 ; p<0.04\right)$. The no-treatment condition (broken line) showed no significant differences $\left(F_{(1,9)}=0.09 ; p=0.895\right)$. The crucial role of verbal suggestion in this decrease is shown by the white circles, which represent the effects of the opposite verbal instruction (placebo). In fact, no nocebo effect occurred if a sham increase was performed $\left(F_{(1,9)}=0.24 ; p=0.614\right)$. Thus, in this case also, the outcome of a sham procedure depended on the verbal instructions. 

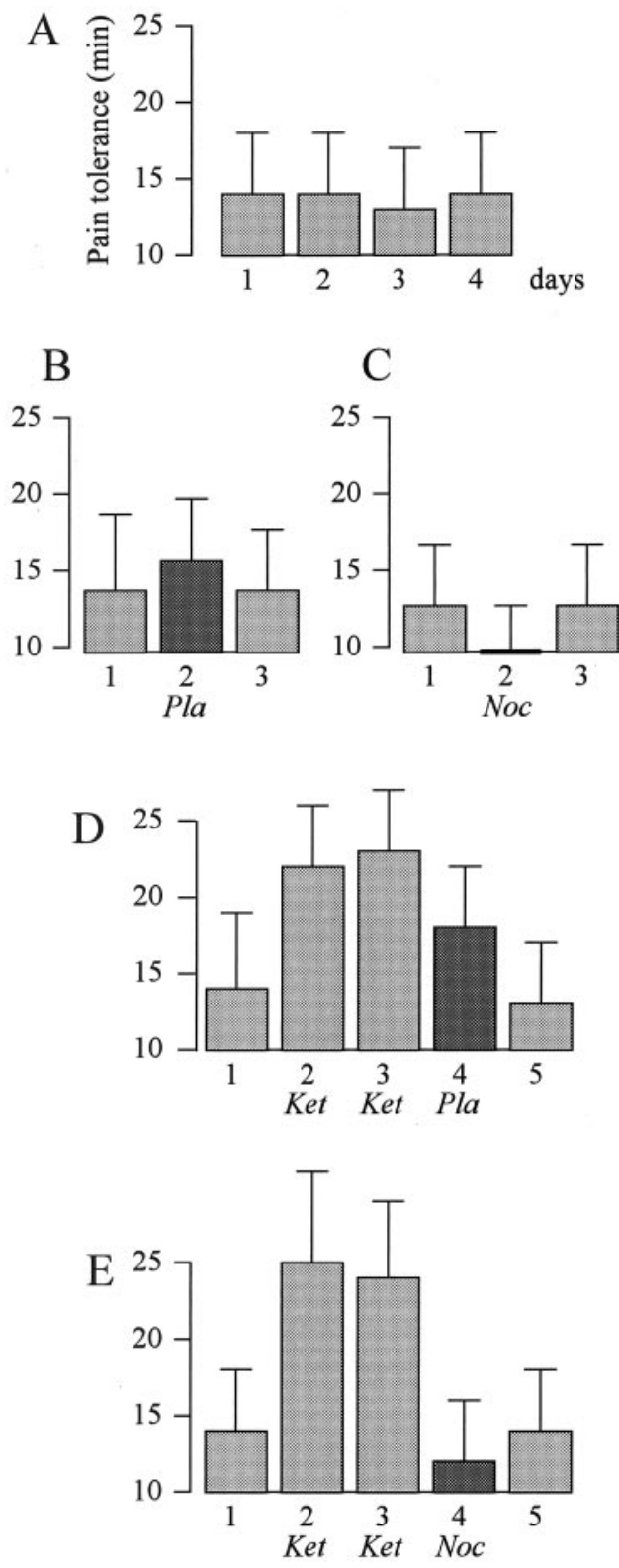

Figure 2. The effects of verbally induced expectations and pharmacological conditioning on pain tolerance. $A$, Natural history of tolerance to ischemic arm pain over 4 consecutive days. $B$, Verbal suggestion of analgesia (placebo) on day 2 induces an increase in tolerance. $C$, Suggestion of hyperalgesia (nocebo) on day 2 induces a decrease in tolerance. D, Suggestion of analgesia on day 4 after a 2 d preconditioning with ketorolac (ket) induces a larger increase in tolerance than verbal suggestion alone in $B$. E, The same ketorolac preconditioning is totally ineffective, however, if suggestion of hyperalgesia is given on day 4. Pla, Placebo; Noc, nocebo.

\section{Hormones}

The natural history of GH and cortisol plasma concentrations is shown in Figure 4. GH concentrations did not show significant changes over the $3 \mathrm{~d}$ period $\left(F_{(6,84)}=0.823, p=0.555\right.$ on day 1 ; $F_{(6,84)}=0.332, p=0.918$ on day $2 ; F_{(6,84)}=0.44, p=0.850$ on day 3). Similarly, cortisol showed no significant changes $\left(F_{(6,84)}=1.054, p=0.397\right.$ on day $1 ; F_{(6,84)}=0.372, p=0.895$ on day $2 ; F_{(6,84)}=1.419, p=0.217$ on day 3$)$.

When suggestion of $\mathrm{GH}$ increase was given (Fig. $5 A$ ), no change in plasma concentration was found over a $75 \mathrm{~min}$ period $\left(F_{(5,40)}=1.872 ; p=0.121\right)$. Likewise, when suggestion of $\mathrm{GH}$ decrease was given (Fig. $5 B$ ), no change in plasma concentration occurred $\left(F_{(5,50)}=0.419 ; p=0.833\right)$. However, if suggestion of

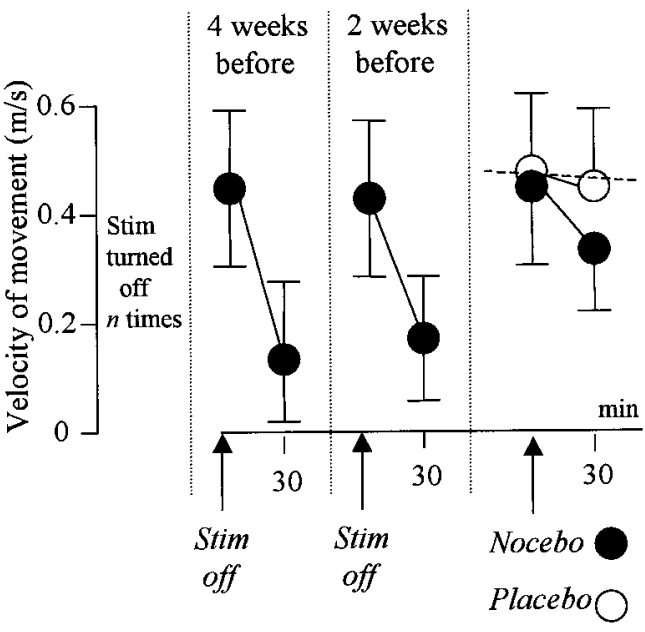

Figure 3. The effects of verbally induced expectations on motor performance in Parkinsonian patients with implanted stimulating electrodes in the subthalamic nuclei. After the stimulator (Stim) had been turned off several times, a sham turning off (nocebo) induces a velocity decrease ( $)$. This decrease is completely blocked $(\bigcirc)$ by the opposite verbal instruction (placebo). The broken line represents the natural history.
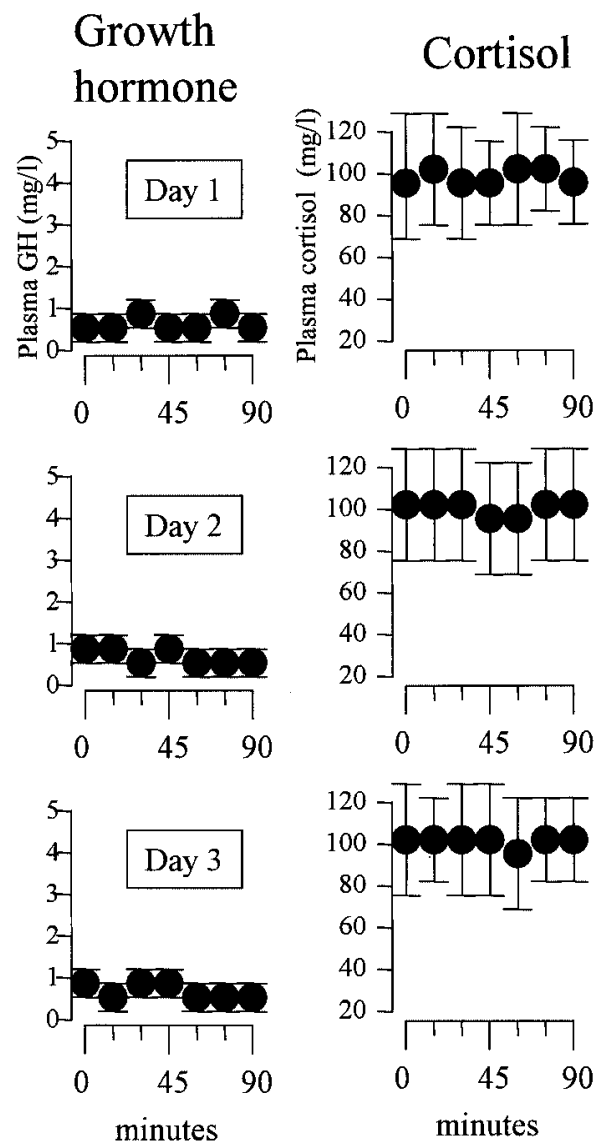

Figure 4. Natural history of $\mathrm{GH}(A)$ and cortisol $(B)$ plasma concentrations for 3 consecutive days. Note that the mean concentrations do not change either during an observation period of $90 \mathrm{~min}$ or over a period of $3 \mathrm{~d}$.

$\mathrm{GH}$ increase was given after a $2 \mathrm{~d}$ preconditioning with sumatriptan (Fig. 5C), a significant increase in GH plasma concentration occurred $\left(F_{(5,40)}=22.618 ; p<0.001\right)$. The post hoc Dunnett test showed that there was a significant increase at both $15 \min \left(q_{(40)}=3.643 ; p<0.03\right)$ and $30 \min \left(q_{(40)}=2.854 ; p<\right.$ 

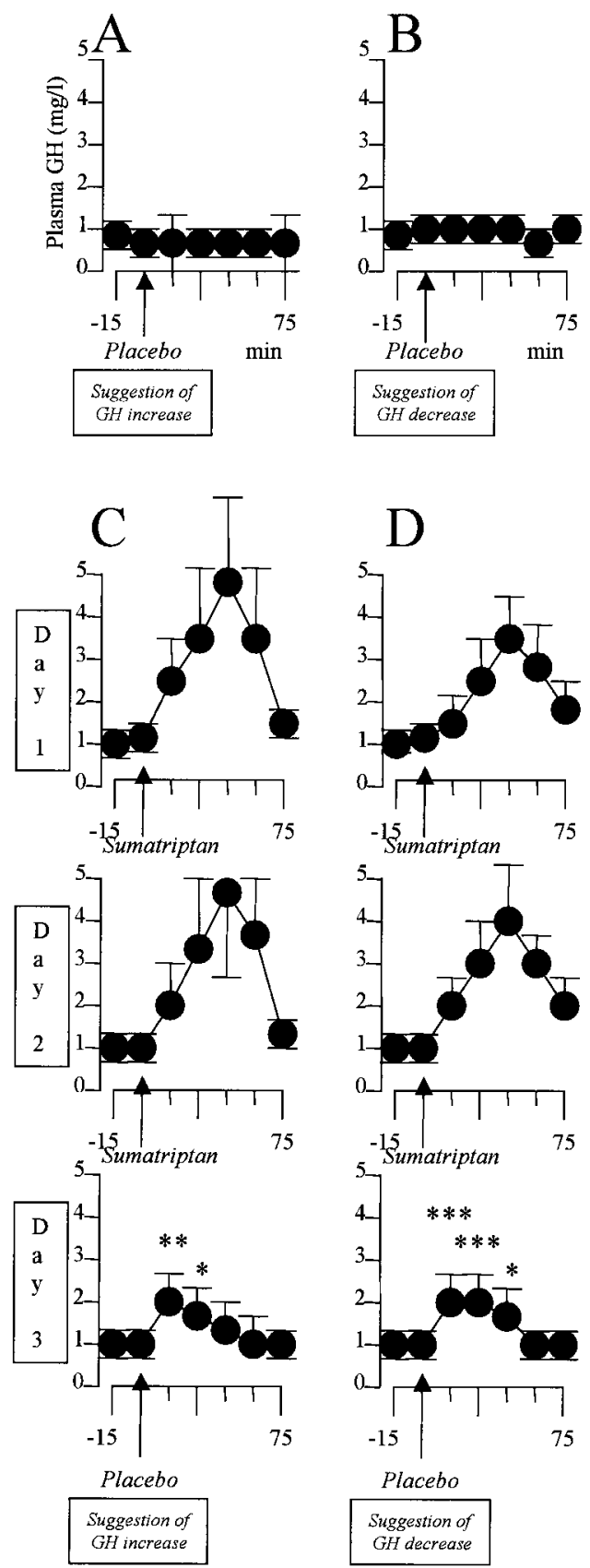

Figure 5. Verbal suggestions of $\mathrm{GH}$ increase $(A)$ and decrease $(B)$ have no effect on $\mathrm{GH}$ plasma concentration. C, After $2 \mathrm{~d}$ of sumatriptan preconditioning, suggestion of $\mathrm{GH}$ increase (Placebo) mimics the effects of sumatriptan. D, This effect is not caused by the suggestion itself, however, because the same sumatriptan-like effect is present after the opposite verbal instruction. ${ }^{*} p<0.05 ;{ }^{* *} p<0.03 ;{ }^{* * *} p<0.01$.

0.05). Thus the placebo GH increase on day 3 mimicked the effect of sumatriptan of the previous days. That this increase was not caused by the verbal suggestion per se is shown in Figure 5D. In fact, the same GH increase was present when suggestion of decrease was given $\left(F_{(5,50)}=29.258 ; p<0.001\right)$. This increase occurred at $15 \min \left(q_{(50)}=7.865 ; p<0.01\right), 30 \mathrm{~min}\left(q_{(50)}=7.131\right.$; $p<0.01)$, and $45 \min \left(q_{(50)}=2.412 ; p<0.05\right)$.

The same effects were observed for cortisol, but in the opposite direction. Suggestion of cortisol decrease (Fig. 6A) or increase (Fig. $6 B$ ) did not have any effect on cortisol plasma concentration $\left(F_{(6,48)}=0.421, p=0.861\right.$ and $F_{(6,54)}=1.894, p=$

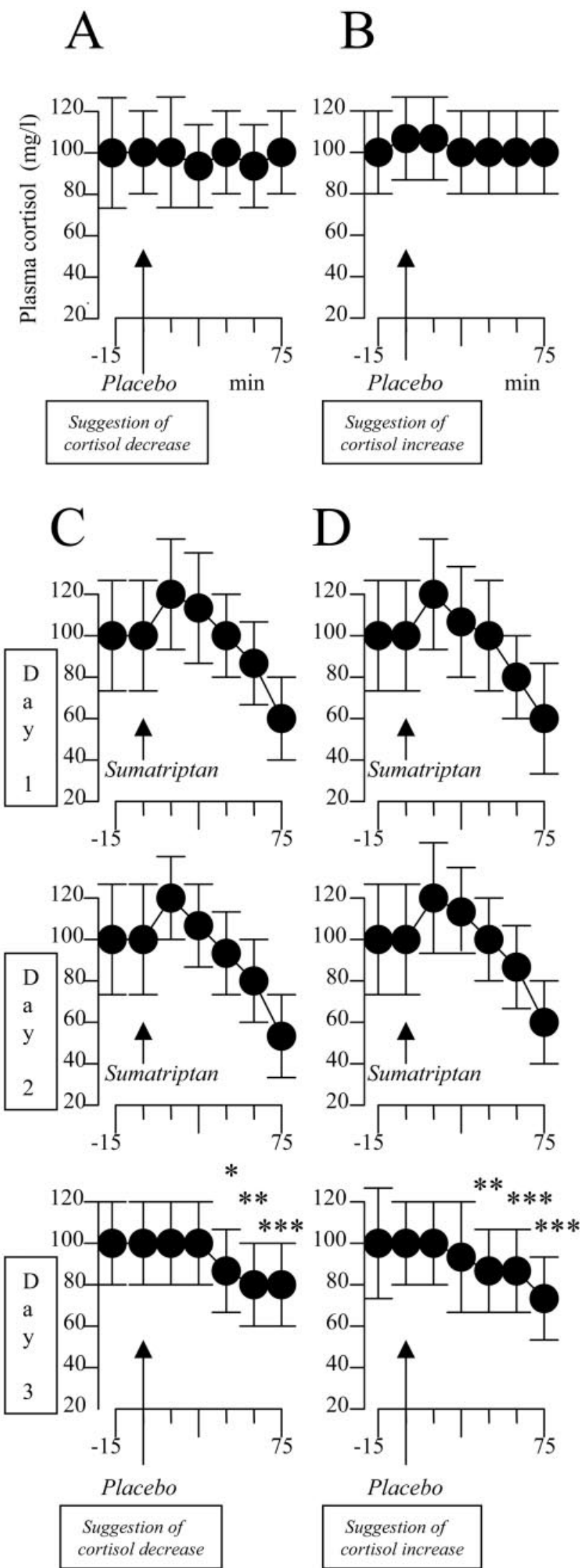

Figure 6. Verbal suggestions of cortisol decrease $(A)$ and increase $(B)$ have no effect on cortisol plasma concentration. C, After $2 \mathrm{~d}$ of sumatriptan preconditioning, suggestion of cortisol decrease (Placebo) mimics the effects of sumatriptan. $D$, This effect is not caused by the suggestion itself, however, because the same sumatriptan-like effect is present after the opposite verbal instruction. ${ }^{*} p<0.04 ;{ }^{* *} p<0.02 ;{ }^{* * *} p<0.01$ 
0.101 , respectively). Conversely, sumatriptan preconditioning on days 1 and 2 induced a placebo cortisol decrease on day 3 , regardless of the verbal suggestions (Fig. 6C,D). In fact, suggestion of cortisol decrease was accompanied by cortisol decrease $\left(F_{(5,45)}=\right.$ $37.642 ; p<0.001)$ at $45 \mathrm{~min}\left(q_{(45)}=4.498 ; p<0.04\right), 60 \mathrm{~min}$ $\left(q_{(45)}=6.746 ; p<0.02\right)$, and $75 \min \left(q_{(45)}=10.894 ; p<0.01\right)$ (Fig. $6 C$ ), and suggestion of cortisol increase was accompanied by cortisol decrease $\left(F_{(5,50)}=43.251 ; p<0.001\right)$ at $45 \mathrm{~min}\left(q_{(50)}=\right.$ $6.047 ; p<0.02)$, $60 \mathrm{~min}\left(q_{(50)}=8.165 ; p<0.01\right)$, and $75 \mathrm{~min}$ $\left(q_{(50)}=12.594 ; p<0.01\right)$ (Fig. 6D).

\section{Discussion}

The present study was aimed at analyzing the role of conditioning and cognitive factors in different placebo responses, in which both subjective and objective measurements were performed. At least two main findings can be identified. First, analgesic and motor placebo responses appear to be mediated by verbally induced expectations. In fact, although we did not assess the subjects' expectations directly, verbal suggestions affect expectations, as suggested by many studies (Kirsch and Weixel, 1988; Benedetti et al., 1999b; Pollo et al., 2001; Benedetti, 2002). Opposite verbal suggestions modulated pain in opposing directions (Fig. $2 B, C$ ), and most important, even after a pharmacological analgesic preconditioning, a significant hyperalgesic effect occurred when suggestion of pain increase was given (Fig. $2 E$ ). This indicates that the placebo effect of Figure $2 D$ was caused by expectation of analgesia and not by the pharmacological preconditioning per se. This can also be seen in Parkinsonian patients, whose motor worsening shown in Figure $3 A$ appears to depend on verbally induced expectation; in fact, the opposite verbal suggestion was sufficient to reverse this effect (Fig. $3 B$ ). The second important finding is that verbally induced expectations of hormonal increase and decrease had no effect on hormonal plasma concentrations. However, placebo administration after sumatriptan preconditioning mimicked the effects of the sumatriptan itself. It is important to point out that these sumatriptan-like effects occurred regardless of whether verbal suggestions were given for $\mathrm{GH}$ increase or decrease. Thus verbal manipulations that are likely to affect expectations did not influence hormonal secretion.

It is also worth noting that the occurrence of hormonal placebo responses indicate that the placebo effect is present not only in regard to subjective measurement, such as pain, but also for objective outcomes as well. Although pharmaco-conditioning is a widely recognized phenomenon in both animals and humans (Ader, 1985, 1997; Siegel, 1985, 2002), our findings clearly demonstrate that the exposure to a biologically active medication (sumatriptan) makes a subsequently administered placebo effective. Because expectations had no effect on hormonal secretion, conditioning mechanisms were likely to be involved. In other words, contextual cues (the subcutaneous injection procedure) were likely to represent the conditioned stimulus, whereas the sumatriptan itself was the unconditioned stimulus.

Our interpretation of these findings is shown in Figure 7. Although expectations are capable of influencing conscious physiological processes such as pain and motor performance, they have no effect on unconscious biological functions such as hormonal secretion, which is affected, however, by a conditioning procedure. Figure 7 also shows that although a conditioning procedure also affects pain and motor performance, it is likely to act through expectations. This is in accordance with alternative theories of learning which suggest that cognitive elements are involved in Pavlovian conditioning. In other words, conditioning would lead to the expectation that a given event will follow an-

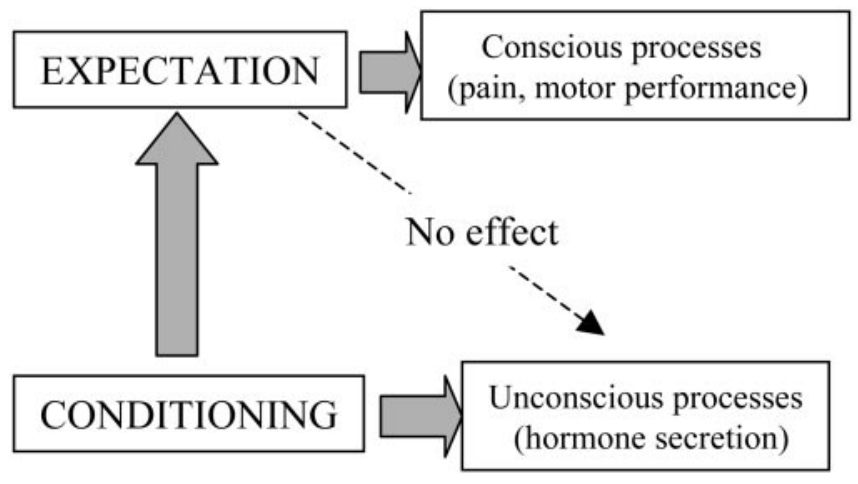

Figure 7. Model to explain the findings of the present study. During a placebo procedure, conscious physiological processes, such as pain and motor performance, are affected by verbally induced expectations, even though a conditioning procedure is performed. By contrast, unconscious physiological processes, such as hormone secretion, are totally unaffected by expectations, whereas they are influenced by placebos through unconscious conditioning mechanisms.

other event, and this occurs on the basis of the information that the conditioned stimulus provides about the unconditioned stimulus (Reiss, 1980; Rescorla, 1988). It is worth remembering a study by Montgomery and Kirsch (1997), who suggested that a conditioned placebo response can result from conditioning but is actually mediated by expectancy.

In recent years, the neurobiological study of the placebo effect has yielded important information about the influence of psychological factors on several body functions such as pain (Amanzio and Benedetti, 1999; Benedetti et al., 1999b; Petrovic et al., 2002; Pollo et al., 2003), motor performance (de la FuenteFernandez et al., 2001; Pollo et al., 2002), and mood (Leuchter et al., 2002; Mayberg et al., 2002). The involvement of endogenous substances, such as opioids (Amanzio and Benedetti, 1999), dopamine (de la Fuente-Fernandez et al., 2001), and serotonin (Mayberg et al., 2002), in the placebo responses indicates that the placebo effect represents a good model for understanding the intricate mechanisms underlying complex mental functions. However, what triggers the release of these endogenous substances during a placebo procedure is still a matter of debate. At least two mechanisms can be involved.

On the one hand, the conditioning theory proposes that the placebo response is a conditioned response caused by repeated associations between a conditioned stimulus and an unconditioned stimulus (Gleidman et al., 1957; Herrnstein, 1962; Wickramasekera, 1980; Siegel, 1985, 2002; Voudouris et al., 1985, 1989, 1990; Ader, 1997). In this case, contextual cues represent the conditioned stimulus (the shape and color of pills, the syringes, the environment of the hospital, and such), whereas active treatments represent the unconditioned stimulus. On the other hand, the cognitive theory assumes that expectations, beliefs, and desire for pain relief play an essential role (Kirsch, 1985, 1999; Price and Fields, 1997; Price, 2000). In fact, some studies showed that different verbal instructions lead to different expectations and thus to different responses, and this plays a fundamental role in the placebo effect (Kirsch, 1985, 1999; Price and Fields, 1997). This occurs not only with placebos but even with active drugs, such as hormones (Wied, 1953), epinephrine (Schachter and Singer, 1962), amphetamine and chloral hydrate (Lyerly et al., 1964), and carisoprodol (Flaten et al., 1999). In fact, a typical drug effect can sometimes be reduced if the subjects are misinformed on the action of the drug, and, similarly, new responses can be elicited (e.g., side effects) with the appropriate verbal in- 
structions. Another study showed that different expectations produce different outcomes after the administration of either caffeinated or decaffeinated coffee (Kirsch and Weixel, 1988), and the same experimental approach has been used recently in the clinical setting by Pollo et al. (2001), who found that the placebo response was much stronger after deceptive administration compared with double-blind administration. These studies emphasize once again that different verbal instructions produce different expectations.

In the present study, we show that conscious expectation and unconscious conditioning are involved in different circumstances and that this is true not only for placebos but for nocebos as well. In fact, placebos may also produce negative outcomes, a situation that has been called the nocebo effect (Kennedy, 1961; Kissel and Barrucand, 1964; Hahn, 1985, 1997; Benedetti et al., 1997). Thus our work indicates that the same mechanisms are involved in an effect that is opposite to the placebo. This is particularly evident for hyperalgesia and motor worsening, in which negative expectations yielded negative outcomes.

The differentiation between expectation and conditioning is important for several reasons. First and foremost, it is important to emphasize that a placebo is an inert treatment within a medical context, and it is this context that represents the crucial element for the placebo response (Benedetti, 2002). As argued in the present study, the context either can act as a conditioned stimulus to produce unconscious conditioned hormonal responses or can have a conscious meaning that induces conscious expectations. In this regard, it is worth remembering that Moerman (2002) proposed to replace the word "placebo response" with "meaning response" to better clarify that it is the meaning that represents the crucial element in the placebo response. From our findings, however, the meaning response appears to be true only in some situations, such as pain and motor performance, whereas a completely unconscious process seems to be involved in hormonal placebo responses.

The best proof of the importance of the context is shown by the comparison between open and hidden medical treatments (Levine et al., 1981; Levine and Gordon, 1984; Amanzio et al., 2001; Benedetti et al., 2003). An open injection of a painkiller in full view of the patient, which represents usual medical practice, is more effective than a hidden injection. This hidden procedure completely eliminates the context associated with the knowledge that a pharmacological agent is being injected. The difference between the outcome of an open and hidden injection represents the placebo effect, at least its major component, which results from the patient's perception of the administration of the agent (Price, 2001). At the present we do not know whether this is true for unconscious physiological processes as well. It will be interesting to determine whether open and hidden administrations of drugs have different effects on hormonal secretion.

Thus the placebo effect seems to be a phenomenon that can be learned either consciously or unconsciously. In the first case, an increased expectation is likely to occur after repeated associations of contextual cues with the outcome, as emphasized by Reiss (1980) and Rescorla (1988). In the second case, a mechanism of Pavlovian conditioning is likely to be involved, in which contextual cues and outcomes are unconsciously associated because of their contiguity. Pavlovian conditioning is important in the placebo responses of animals (Herrnstein, 1962; Ader, 1985, 1997; Siegel, 1985, 2002), in which the conscious processes are supposed to be absent or at least much less important. Likewise, as shown in the present study, conditioning appears to play a crucial role in the placebo responses of human unconscious physiologi- cal functions, whereas expectations replace conditioning when conscious perception is involved (e.g., pain and motor performance). We believe that these analogies and differences between animals and humans may represent an interesting starting point to better understand analogies and differences between unconscious and conscious processes.

\section{References}

Ader R (1985) Conditioned immunopharmacological effects in animals: implications for a conditioning model of pharmacotherapy. In: Placebo: theory, research, and mechanisms (White L, Tursky B, Schwartz GE, eds), pp 306-323. New York: Guilford.

Ader R (1997) The role of conditioning in pharmacotherapy. In: The placebo effect: an interdisciplinary exploration (Harrington A, ed), pp 138165. Cambridge, MA: Cambridge UP.

Amanzio M, Benedetti F (1999) Neuropharmacological dissection of placebo analgesia: expectation-activated opioid systems versus conditioning-activated specific subsystems. J Neurosci 19:484-494.

Amanzio M, Pollo A, Maggi G, Benedetti F (2001) Response variability to analgesics: a role for non-specific activation of endogenous opioids. Pain 90:205-215.

Benazzouz A, Hallett M (2000) Mechanism of action of deep brain stimulation. Neurology 55:S13-16.

Benedetti F (1996) The opposite effects of the opiate antagonist naloxone and the cholecystokinin antagonist proglumide on placebo analgesia. Pain 64:535-543.

Benedetti F (2002) How the doctor's words affect the patient's brain. Eval Health Prof 25:369-386.

Benedetti F, Amanzio M, Casadio C, Oliaro A, Maggi G (1997) Blockade of nocebo hyperalgesia by the cholecystokinin antagonist proglumide. Pain 70:431-436.

Benedetti F, Amanzio M, Baldi S, Casadio C, Maggi G (1999a) Inducing placebo respiratory depressant responses in humans via opioid receptors. Eur J Neurosci 11:625-631.

Benedetti F, Arduino C, Amanzio M (1999b) Somatotopic activation of opioid systems by target-directed expectations of analgesia. J Neurosci 19:3639-3648.

Benedetti F, Maggi G, Lopiano L, Lanotte M, Rainero I, Vighetti S, Pollo A (2003) Open versus hidden medical treatments: the patient's knowledge about a therapy affects the therapy outcome. Prevention and Treatment, in press.

de la Fuente-Fernandez R, Ruth TJ, Sossi V, Schulzer M, Calne DB, Stoessl AJ (2001) Expectation and dopamine release: mechanism of the placebo effect in Parkinson's disease. Science 293:1164-1166.

Entwisle SJ, Fowler PA, Thomas M, Eckland DJA, Lettis S, York M, Freedman PS (1995) The effects of oral sumatriptan, 5HT1 receptor agonist, on circulating ACTH and cortisol concentrations in man. Br J Clin Pharmacol 39:389-395.

Fahn S, Elton RL, and the Members of the UPDRS Development Committee (1987) Unified Parkinson's Disease Rating Scale. In: Recent developments in Parkinson's disease (Fahn S, Marsden CD, Calne DB, eds), pp 153-163. London: MacMillan.

Flaten MA, Simonsen T, Olsen H (1999) Drug-related information generates placebo and nocebo responses that modify the drug response. Psychosomat Med 61:250-255.

Franceschini R, Cataldi A, Garibaldi A, Cianciosi P, Scordamaglia A, Barreca T, Rolandi E (1994) The effects of sumatriptan on pituitary secretion in man. Neuropharmacology 33:235-239.

Gleidman LH, Grantt WH, Teitelbaum HA (1957) Some implications of conditional reflex studies for placebo research. Am J Psychiat 113:1103-1107.

Grevert P, Albert LH, Goldstein A (1983) Partial antagonism of placebo analgesia by naloxone. Pain 16:129-143.

Hahn RA (1985) A sociocultural model of illness and healing. In: Placebo: theory, research, and mechanisms (White L, Tursky B, Schwartz GE, eds), pp 167-195. New York: Guilford.

Hahn RA (1997) The nocebo phenomenon: scope and foundations. In: The placebo effect: an interdisciplinary exploration (Harrington A, ed), pp 56-76. Cambridge, MA: Harvard UP.

Herrnstein RJ (1962) Placebo effect in the rat. Science 138:677-678. 
Hutchinson WD, Allan RJ, Opitz H, Levy R, Dostrovsky JO, Lang AE, Lozano AM (1998) Neurophysiological identification of the subthalamic nucleus in surgery for Parkinson's disease. Ann Neurol 44:622-628.

Kennedy WP (1961) The nocebo reaction. Med World 91:203-205.

Kirsch I (1985) Response expectancy as a determinant of experience and behavior. Am Psychol 40:1189-1202.

Kirsch I (1999) How expectancies shape experience. Washington, DC: American Psychological Association.

Kirsch I, Weixel LJ (1988) Double-blind versus deceptive administration of a placebo. Behav Neurosci 102:319-323.

Kissel P, Barrucand D (1964) Placebos et effet placebo en medecine. Paris: Masson.

Laska E, Sunshine A (1973) Anticipation of analgesia: a placebo effect. Headache 13:1-11.

Leuchter AF, Cook IA, Witte EA, Morgan M, Abrams M (2002) Changes in brain function of depressed subjects during treatment with placebo. Am J Psychiat 159:122-129.

Levine JD, Gordon NC (1984) Influence of the method of drug administration on analgesic response. Nature 312:755-756.

Levine JD, Gordon NC, Fields HL (1978) The mechanisms of placebo analgesia. Lancet 2:654-657.

Levine JD, Gordon NC, Smith R, Fields HL (1981) Analgesic responses to morphine and placebo in individuals with postoperative pain. Pain 10:379-389.

Limousin P, Krack P, Pollak P, Benazzouz A, Ardouin C, Hoffmann D, Benabid AL (1998) Electrical stimulation of the subthalamic nucleus in advanced Parkinson's disease. N Engl J Med 339:1105-1111.

Lopiano L, Rizzone M, Bergamasco B, Tavella A, Torre E, Perozzo P, Valentini MC, Lanotte M (2001) Deep brain stimulation of the subthalamic nucleus: clinical effectiveness and safety. Neurology 56:52-54.

Lyerly SB, Ross S, Krugman AD, Clyde DJ (1964) Drugs and placebos: the effects of instructions upon performance and mood under amphetamine sulphate and chloral hydrate. J Abn Soc Psychol 68:321-327.

Mayberg HS, Silva AJ, Brannan SK, Tekell JL, Mahurin RK, McGinnis S, Jerabek PA (2002) The functional neuroanatomy of the placebo effect. Am J Psychiat 159:728-737.

Moerman DE (2002) Explanatory mechanisms for placebo effects: cultural influences and the meaning response. In: The science of the placebo: toward an interdisciplinary research agenda (Guess HA, Kleinman A, Kusek JW, Engel LW, eds), pp 77-107. London: BMJ Books.

Montgomery GH, Kirsch I (1997) Classical conditioning and the placebo effect. Pain 72:107-113.

Mota A, Bento A, Penalva A, Pombo M, Dieguez C (1995) Role of the serotonin receptor subtype $5-\mathrm{HT}_{1 \mathrm{D}}$ on basal and stimulated growth hormone secretion. J Clin Endocrinol Metab 80:1973-1977.

Petrovic P, Kalso E, Petersson KM, Ingvar M (2002) Placebo and opioid analgesia-imaging a shared neuronal network. Science 295:1737-1740.

Pollo A, Amanzio M, Arslanian A, Casadio C, Maggi G, Benedetti F (2001) Response expectancies in placebo analgesia and their clinical relevance. Pain 93:77-84.

Pollo A, Torre E, Lopiano L, Rizzone M, Lanotte M, Cavanna A, Bergamasco B, Benedetti F (2002) Expectation modulates the response to subthalamic nucleus stimulation in Parkinsonian patients. NeuroReport 13:1383-1386.

Pollo A, Vighetti S, Rainero I, Benedetti F (2003) Placebo analgesia and the heart. Pain 102:125-133.

Price DD (2000) Factors that determine the magnitude and presence of pla- cebo analgesia. In: Proceedings of the 9th World Congress of Pain (Devor M, Rowbotham MC, Wiesenfeld-Hallin Z, eds), pp 1085-1095. Seattle, WA: IASP.

Price DD (2001) Assessing placebo effects without placebo groups: an untapped possibility? Pain 90:201-203.

Price DD (2002) Endogenous opioid and non-opioid pathways as mediators of placebo analgesia. In: The science of the placebo: toward an interdisciplinary research agenda (Guess HA, Kleinman A, Kusek JW, Engel LW, eds), pp 183-206. London: BMJ Books.

Price DD, Fields HL (1997) The contribution of desire and expectation to placebo analgesia: implications for new research strategies. In: The placebo effect: an interdisciplinary exploration (Harrington A, ed), pp 117137. Cambridge, MA: Harvard UP.

Price DD, Milling LS, Kirsch I, Duff A, Montgomery GH, Nicholls SS (1999) An analysis of factors that contribute to the magnitude of placebo analgesia in an experimental paradigm. Pain 83:147-156.

Rainero I, Valfrè W, Savi L, Gentile S, Pinessi L, Gianotti L, Arvat E, Ghigo E, Del Rizzo P, Calvelli P, Limone P (2001) Neuroendocrine effects of subcutaneous sumatriptan in patients with migraine. J Endocrinol Invest 24:310-315.

Rainero I, Valfrè W, Savi L, Ferrero M, Del Rizzo P, Limone P, Isaia GC, Gianotti L, Pollo A, Verde R, Benedetti F, Pinessi L (2002) Decreased sensitivity of $5-\mathrm{HT}_{1 \mathrm{D}}$ receptors in chronic tension-type headache. Headache 42:709-714.

Reiss S (1980) Pavlovian conditioning and human fear: an expectancy model. Behav Ther 11:380-396.

Rescorla RA (1988) Pavlovian conditioning: it's not what you think it is. Am Psychol 43:151-160.

Rizzone M, Lanotte M, Bergamasco B, Tavella A, Torre E, Faccani G, Melcarne A, Lopiano L (2001) Deep brain stimulation of the subthalamic nucleus in Parkinson's disease: effects of variation in stimulation parameters. J Neurol Neurosurg Psychiat 71:215-219.

Schachter S, Singer JE (1962) Cognitive, social and physiological determinants of emotional states. Psychol Rev 69:379-399.

Siegel S (1985) Drug-anticipatory responses in animals. In: Placebo: theory, research, and mechanisms (White L, Tursky B, Schwartz GE, eds), pp 288-305. New York: Guilford.

Siegel S (2002) Explanatory mechanisms for placebo effects: Pavlovian conditioning. In: The science of the placebo: toward an interdisciplinary research agenda (Guess HA, Kleinman A, Kusek JW, Engel LW, eds), pp 133-157. London: BMJ Books.

Valverde I, Penalva A, Dieguez C (2000) Influence of different serotonin receptor subtypes on growth hormone secretion. Neuroendocrinology 7:145-153.

Voudouris NJ, Peck CL, Coleman G (1985) Conditioned placebo responses. J Perspect Soc Psychol 48:47-53.

Voudouris NJ, Peck CL, Coleman G (1989) Conditioned response models of placebo phenomena: further support. Pain 38:109-116.

Voudouris NJ, Peck CL, Coleman G (1990) The role of conditioning and expectancy in the placebo response. Pain 43:121-128.

Wickramasekera I (1980) A conditioned response model of the placebo effect: predictions from the model. Biofeed Self-Regul 5:5-18.

Wied GI (1953) Uber die Bedeutung der Suggesstion in der Therapie klimatkerischer Ausfallerscheinungen. ArztlicheWochenschrift 8:623-625.

Zappia M, Montesanti R, Colao R, Quattrone A (1994) Usefulness of movement time in the assessment of Parkinson's disease. J Neurol 241:543-550. 